\title{
Discussion On the Key Problems in the Course Reform of Wushu and National Traditional Sports Major
}

\author{
Zhou Jicheng \\ Zhuhai College of Jilin University, Guangdong, Zhuhai, 519041
}

Keywords: Wushu; national traditional sports; reform

\begin{abstract}
Wushu and national traditional sports major is a key professional course in China's colleges and universities. It is mainly to cultivate high-quality Wushu talents for the society. However, judging from the current situation, there are many deficiencies and problems in the teaching of martial arts and national traditional sports, which has seriously affected the effective realization of teaching goals. This paper analyzes the above problems and puts forward the corresponding personnel training objectives. Based on this, it discusses the reform of the curriculum structure of Wushu and traditional sports.
\end{abstract}

\section{Introduction}

In 1986, the former State Education Commission included martial arts in the curriculum of ordinary higher education institutions. In 1998, the Ministry of Education promulgated a new college undergraduate professional catalog, which broadened the martial arts profession into a national traditional sports specialty and became a newly established one. Undergraduate. Nowadays, national traditional sports has gradually formed a discipline structure system with its own teaching characteristics, and has received extensive attention from the society. However, due to various factors, the national traditional sports specialty curriculum has problems such as fixed training objectives and single curriculum setting, which affects the continuous and healthy development of the profession and requires the attention and solution of relevant education staff [1].

\section{Related Concepts of Martial Arts and Traditional Sports}

National traditional sports refer to sports that have developed before China's modern times, practiced and passed down or influenced by Chinese people from generation to generation, and are the sports activities of health, fitness, recreation and entertainment accumulated by the people of all ethnic groups in China during long-term production and living practices. The general term is an important part of our national traditional culture and it is characterized by inheritance, custom and folk custom. The definition of the extension of the national traditional sports includes several aspects: First, sports that occur in individual or part of the nation and has maintained its unique personality and limited inheritance, such as Ryukyu, etc.; second, it has developed in ancient and ancient China. And it retains a relatively fixed form that affects today's sports or similar sports activities, such as archery, etc. Third, it has emerged in various ethnic groups in China and gradually developed into a popular sport in China and even the world, such as martial arts, dragon boats, and so on. At present, many colleges and universities in our country have set up martial arts and national traditional sports majors, mainly to cultivate and meet the needs of the socialist market economy. They have the skills and skills of traditional national sports teaching, training, scientific research, and can engage in martial arts, sports health, and nationalities. Professional sports professionals working in traditional folk sports include employment of martial arts coaches, fitness instructors, and management personnel at all levels. The number of Chinese martial arts learning is shown in the figure below. 


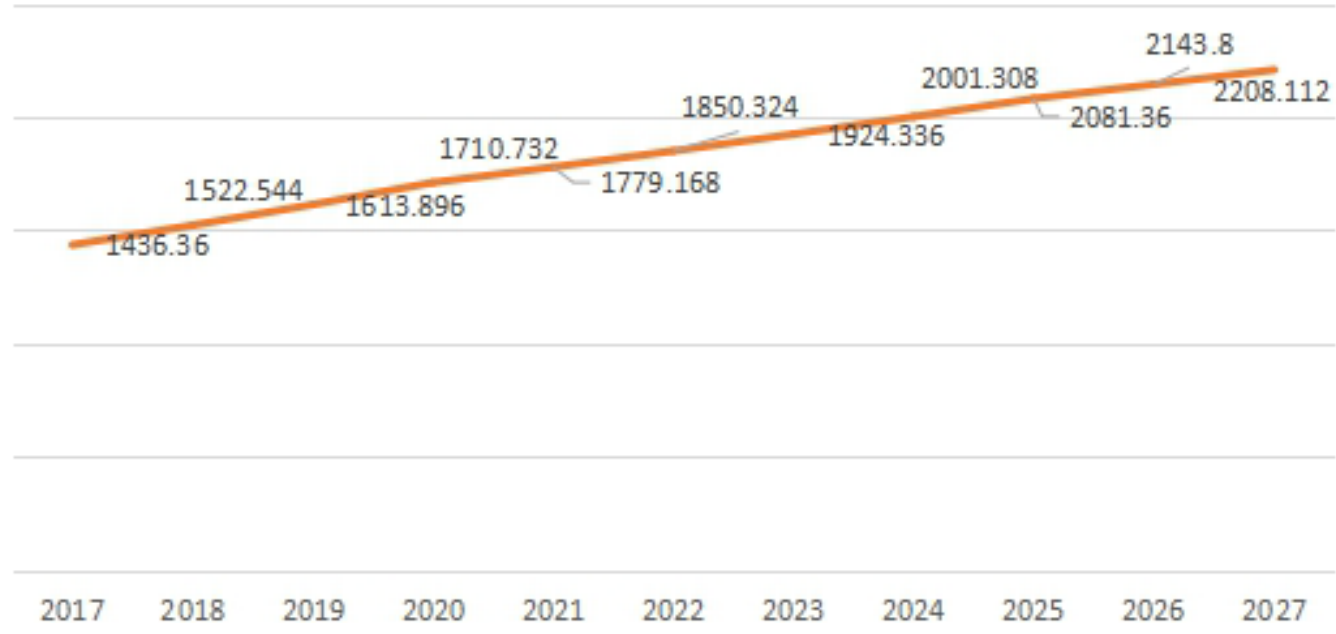

Fig.1 Number of Chinese martial arts learning

\section{Problems in the Teaching of Martial Arts and National Traditional Sports Major}

\subsection{Lack of reasonable training objectives}

In education and teaching, the setting of training objectives is very important and is the starting point and destination of all work. In our country's Current Undergraduate Professional Catalogue and Professional Introduction, it is clearly stated that the teaching goal of the Wushu and traditional sports majors is to cultivate traditional sports teaching, training, professional skills, scientific research knowledge, and to be able to engage in martial arts. Martial arts talents who work in sports and fitness guidance. However, many colleges and universities currently regard traditional ethnic sports as a kind of pure martial arts or sports. When setting up training goals, there is a one-sided phenomenon, and some colleges and universities do not follow the training objectives in teaching, which affects the The development of Wushu and the national traditional sports specialty [2].

\subsection{Lack of effective curriculum structure}

At present, the curriculum structure of martial arts and national traditional sports majors in many colleges and universities in China is based on the reference of other sports majors, and the need for "professional education" is taken as the logic starting point for the curriculum structure setting. Whether it is the construction of a curriculum structure or the setting of various courses or courses The selection of curriculum content needs to embody the idea and concept of "professional education." In this case, the structure of martial arts and national traditional sports courses is mostly based on martial arts routines and Wushu Sanda. The content of the teaching is cross-repeated and lacks new ideas, and the content of theoretical teaching is relatively single, which affects the quality and efficiency of teaching [3].

\subsection{Improper setting of curriculum}

In the course setting of martial arts and national traditional sports, the ratio of compulsory courses and elective courses has great problems. In general, the proportion of elective courses should be appropriately increased in the course structure reform. However, according to the current development situation, most course systems for martial arts and national traditional sports take the position of the specialty of Wushu, and the proportion of required courses is relatively large, and the proportion of elective courses is insufficient, which affects the improvement of students' overall quality. Course formulas are calculated as follows.

$$
l\left(Z_{i}, X_{j}\right)=\sqrt{\lambda_{i}} a_{i j}(i=1,2, \cdots, m ; j=1,2, \cdots, p)
$$




\section{Effective Measures for the Reform of Curriculum Structure for Wushu and Traditional Sports Education Major}

\subsection{Clear guidelines}

The clarification of the guiding ideology of curriculum structure reform and system optimization is an important prerequisite for achieving teaching reform. In practice, first of all, market needs should be fully considered. The market's demand for ethnic traditional sports professionals is the premise and driving force for the establishment of specialized courses. Under the background of the continuous deepening of current quality education, the setting of national traditional sports professional courses should fully consider the quality requirements of professionals for professionals in a period of time in the future. Demand situation, continuous reform and innovation of the curriculum structure, to meet the actual needs of society. Second, we must develop and improve the professional structure. From the aspect of improving the construction of the national traditional sports specialty, the current emphasis on the curriculum structure of competitive martial arts in the traditional national physical education curriculum in colleges and universities not only affects the overall development of students, but also it is difficult to effectively adapt to the needs of social pluralism. In this regard, relevant teachers should adjust and reform them, absorb and develop advanced national traditional sports culture, introduce more traditional ethnic sports programs into higher physical education institutions, and promote the diversification of professional courses. At the same time, with the current increase in people's awareness of health needs, the demand for traditional ethnic sports professionals in society has begun to develop in a complex and diversified manner. The scope of employment for professionals is also expanding. In view of this situation, it is necessary to expand the content of the traditional teaching of traditional national sports, not only to have professional martial arts content, but also to have corresponding sports health content, and to constantly improve the overall quality of professional talents [4].

\subsection{Optimize the curriculum system}

In education and teaching, the curriculum system is an important carrier of teaching content, which directly determines the knowledge structure and overall quality of educational objects, and also affects the effective realization of teaching objectives. Therefore, aiming at the training target of the current national traditional physical education curriculum, in the process of constructing and optimizing the curriculum structure system, it is necessary to cultivate professional sports with outstanding scientific literacy, skilled sports skills, skilled theoretical methods, and social development. Talent. In the actual teaching process, teachers can take the market demand as the leading factor and take the principle of "optimizing the curriculum system, updating the teaching content, adjusting the knowledge structure, and improving the actual ability" as the guiding ideology, combining the existing teaching conditions and the actual conditions of the students, and Make adjustments and reforms. First, we should proceed from the current curriculum structure system, appropriately increase the proportion of academic hours, reduce the proportion of the hours of technical courses, increase the number of elective courses, reduce the required course hours, and ensure the rationality and reliability of the course structure system; Courses and basic electives are rationally set.

\subsection{Pay attention to theoretical study}

Under the background of current quality education, the training of national traditional sports professionals has the characteristics of "thick basis" and "wide caliber" and should be guaranteed by theoretical study. Judging from the current situation, the national traditional sports majors in China's higher sports colleges are generally enrolled individually, and the theoretical foundation of most students is weak, and there is a serious imbalance between theory and practice. In this regard, physical education institutions should strengthen their theoretical knowledge to supplement and improve. In the teaching activities, it is possible to achieve the "subjectivization" of compulsory courses, break down the barriers between traditional disciplines, carry out corresponding curriculum integration, change the weak and monotonous practice of traditional professional courses, stress 
systemic learning, and improve students' theoretical knowledge. The mastery and application skills promote the all-round development of students.

\section{Summary}

All in all, under the background of the continuous deepening of quality education, the society has put forward higher requirements for the national traditional sports professionals, and the traditional single technical sports personnel can no longer meet the actual needs of society. In this regard, sports academies and colleges should pay sufficient attention to the current problems in the teaching of national traditional physical education curriculum, carry out corresponding reforms of the curriculum structure system, strengthen the cultivation of compound and diversified talents, and lay a solid foundation for the long-term development of students.

\section{Acknowledgement}

Source: Tenth batch of young teachers training program of zhuhai college, Jilin University

\section{References}

[1] Hong Shen Wang, Feng Jun Yang, Yong Lan Fang. Research on the Development Mode for Ethnic Minority Traditional Sports Cultural Resources[J]. Advanced Materials Research, 2012,1480(361).

[2] Yi Wei Liu. On the Bottleneck of the Cultural Value of National Traditional Sports and Solutions[J]. Advanced Materials Research,2014,3530(1044).

[3] Ming Yang, Hao Guo, Jindong Chang, Yujie Shen. Research on Bayu Traditional Sports Development[J]. Open Journal of Social Sciences,2014,02(12).

[4] Guangtian Qian. Study on Protection and Inheritance of Traditional Sports Culture[M]. Springer Berlin Heidelberg:2013-06-15. 